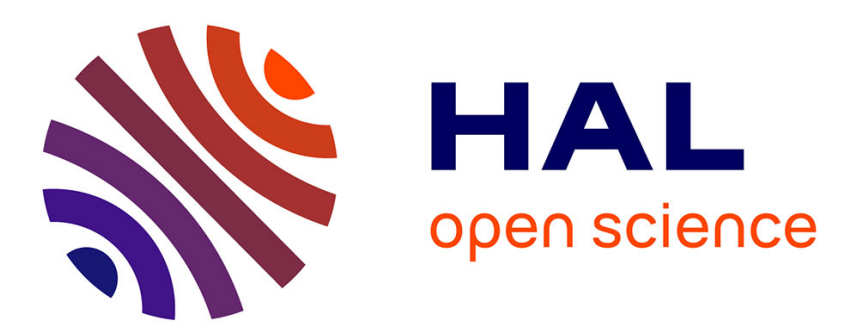

\title{
Residential location choice in a developing country: what matter? A choice experiment application in Burkina Faso
}

Sidnoma Abdoul Aziz Traoré

\section{- To cite this version:}

Sidnoma Abdoul Aziz Traoré. Residential location choice in a developing country: what matter? A choice experiment application in Burkina Faso. Forest Policy and Economics, 2019, 102, pp.1-9. 10.1016/j.forpol.2019.01.021 . hal-02090937

\section{HAL Id: hal-02090937 \\ https://hal.science/hal-02090937}

Submitted on 22 Oct 2021

HAL is a multi-disciplinary open access archive for the deposit and dissemination of scientific research documents, whether they are published or not. The documents may come from teaching and research institutions in France or abroad, or from public or private research centers.
L'archive ouverte pluridisciplinaire HAL, est destinée au dépôt et à la diffusion de documents scientifiques de niveau recherche, publiés ou non, émanant des établissements d'enseignement et de recherche français ou étrangers, des laboratoires publics ou privés.

\section{다(1) $\$$}

Distributed under a Creative Commons Attribution - NonCommerciall 4.0 International 


\title{
Residential location choice in a developing country: what matter? A choice experiment application in Burkina Faso
}

Sidnoma Traoré,

UMR 1135 CEE-M (Univ Montpellier, CNRS, INRA, Montpellier SupAgro) France

2 place Pierre Viala cedex 2, Building 26, 34060 Montpellier/France traoresi@supagro.fr/traoresidnoma@yahoo.fr Phone: 0033 (0) 499612742

\begin{abstract}
This paper assesses the benefits derived from environmental amenities, and more specifically from an urban park, from data on residential location choices. Household decisions regarding their residential location have important implications for urban planning. This paper uses a choice experiment pivot design (CE) to empirically analyse the trade-off between location attributes such as distance to an urban park and distance to workplace in the context of a developing country in which environmental questions are generally considered of lower priority. The limitation of transportation and communication networks suggests that the "tyranny of distance" is even more significant in this particular context than in larger cities located in more developed countries. Results show that inhabitants are willing to pay more in order to live close to an urban park than to their workplace. Furthermore, I find that preferences are heterogeneous and that the attribute corresponding to the presence of relatives in the area is associated with the highest willingness to pay.
\end{abstract}

Keywords: residential location, developing country, urban forest, choice experiment, willingness to pay space

\section{Highlights}

- We study the trade-off between residential location choice attributes

- This is the first analysis of residential location choice in Africa that takes into account distance to an urban park and distance to workplace

- We find that reducing the distance to environmental amenities (i.e. the park) is associated with a higher willingness to pay than reducing the distance to the workplace

- Among all attributes of location choice, the presence of relatives living in the area is associated with the highest willingness to pay 


\section{Introduction}

Urban sprawl and a variety of land use changes have led to environmental impacts that affect not only the sustainability of urban areas, but also the health of the citizens who live there (Barbosa et al., 2012; Dou et al., 2013). The high population density of urban areas creates development pressures on urban green spaces (Jim, 2004) and threatens the amenities they provide to urban residents. As a result, these green spaces have received increasing attention from urban planners, and urban forests are being transformed into parks that offer essential goods and services for urban development (Baur et al. 2013).

Along with many other major cities in developing countries, Ouagadougou (Burkina-Faso) has been experiencing urbanization pressures that result in a significant urban sprawl. This sprawl generates not only transport costs associated with increasing commutes and traffic congestion, but also health costs associated with higher levels of air pollution. Ouagadougou is also home to a large urban park that provides many goods and services to users, and which is currently threatened by the prospect of further residential and industrial development. A prominent local debate is occurring regarding the future of this space. In this context, this paper aims at estimating the importance of environmental amenities in the residential location decisions made by the inhabitants of Ouagadougou.

The main purpose of this paper is to use choice experiment method in order to empirically analyze the importance and values associated with various attributes of residential location choice in the context of a developing country. We are especially interested by the trade-off between living closer to environmental amenities and living closer to the workplace in Burkina Faso in which environmental questions are generally considered of lower priority due to the underdevelopment (Martinez-Alier, 2003). The ongoing development of transport and 
communication infrastructures in Ouagadougou suggests that the constraints associated with distance are of particularly importance for residents of the city (Prager and Thisse, 2010). It is now widely recognized that urban parks and green areas are of substantial importance in the lives of citizens in large cities (Chiesura, 2004). The presence of natural assets such as parks and forests in urban contexts significantly contributes to an improved quality of life among users (Chiesura, 2004; Kuchelmeister and Braatz, 1993; Kuo and Sullivan, 2001).

Many studies have analyzed residential location choices using discrete choice models in the past (Earnhart, 2001, 2006; Kim et al., 2005a; Kim et al., 2005b; Chhetri et al., 2006; Nowotny, 2011; Frenkel et al., 2013; Wu et al., 2013; Tu et al., 2016) ; however, few of them have studied the trade-off between environmental amenities and distance to workplace. According to Nowotny (2011), one important trade-off is that which is made between environmental amenities and distance to workplace. And, to our knowledge, no studies have yet been performed in an African context (see Kim et al. 2005a).

Additionally, the importance of the presence of relatives in the residential area is highlighted. The high cultural value placed on the presence of a strong community suggests that family ties are very important in this location choice. It is in that sense Gervais-Lambony, (1994) stated: "in Africa, city dweller is characterized by loose ties with its significant rural origins and lasting roots in the city".

In this study, we examine residential location choices in the city of Ouagadougou, which contains a natural forest that has been transformed into an urban park called Bãngr-weoogo. The urban commune of Ouagadougou is Burkina Faso's main economic center and has experienced significant environmental degradation over the years. Due to overall losses in the quantity and quality of natural amenities in the city, Bãngr-weoogo (265 Ha) is now considered as an oasis in the desert. Moreover, although the urbanization rate in Burkina Faso ranks it 
among the most rural countries in West Africa, Ouagadougou is home to more than $50 \%$ of the country's urban citizens (a total of 1,626,950 inhabitants residing within 36,600 ha according to the Ministry of urbanization). Housing is thus a growing concern and puts significant development pressure on surrounding lands as well as what remains of the green spaces within the city.

The paper is organized as follows. Section 2 describes related literature as well as the specific characteristics of the area under study. Section 3 presents the methods used for data collection, and describes the survey design and choice experiment. Section 4 presents the econometric specification and the model of willingness to pay and the results of this analysis. Section 5 is devoted to the discussion of the results. The final section concludes with a summary of the main results, highlights implications of these results, and offers our perspective regarding future work on this subject.

\section{Residential location choice literature and housing characteristics in Ouagadougou}

\subsection{Residential location choice literature}

In this section, the literature on the explanatory variables that can influence a household's choice of residential location is surveyed.

Cities' size and structure are the result of a balance between centripetal forces (e.g. natural advantages, market size, etc.) and centrifugal forces (e.g. competition, travel costs, salary costs and land prices, etc.) that affect both the population and economic activities (Krugman, 1996). Choosing a location in which to live is one of the most important decisions made by households, and it impacts the habits of household members as well as the non-members with whom they interact (Sener et al., 2011). 
The urban economics literature indicates that the choice of residential location is the result of a trade-off between accessibility to city services (e.g. jobs, public goods), housing costs, as well as the presence of undesirable nuisances and desirable amenities such as landscapes (Brueckner et al., 1999). Accessibility to the workplace and social quality of the neighborhood are the extrinsic attributes that have been shown to have the greatest impact on residential choice (Cavailhès, 2005). Other studies have highlighted the role of distance from the workplace in housing choice (Horner, 2004, 2003; Kim et al., 2005a), and it has been demonstrated that the remoteness of the workplace has consequences for households in terms of time and money (Nowotny, 2011). Indeed, when distance to the workplace increases, individuals tend to relocate (Renkow and Hoover, 2000; Van Ommeren et al., 1999). However, working in the city while living in the outside the city is an increasingly common part of the modern lifestyle (Cavailhès, 2009). The attractiveness of suburban areas can be explained by preferences for green amenities and the better living environments that larger space generally affords (Cavailhès and Brossard, 2007; Nechyba and Strauss, 1998). Thus, a household's residential location choice can be explained by several factors including but not limited to dwelling size, price, neighborhood, distance to major places of interest, and distance to the workplace. Trade-offs between these factors are an inherent aspect of residential location choice.

Many studies have used theoretical models such as Alonso's (1964) monocentric model in order to explain residential location choices, and empirical models such as hedonic price models in order to value a variety of attributes of residential choices. One of the non-market valuation techniques that allows for an understanding of house location choice is the hedonic price method. This approach identifies the flows of ecosystem services as one of the attributes that contribute to the price of market goods, specifically the price of housing. The discrete choice models developed by McFadden (1978) are an alternative to Alonso's model, which is considered deterministic and relies on the assumption of monocentricity. These types of models 
make it possible to analyze the trade-offs made by households between location choice variables, and to identify the differing sensitivities of various segments of the population to these different attributes (Frenkel et al., 2013).

\subsection{Characteristics in Ouagadougou}

Ouagadougou, the capital of Burkina Faso, is a growing city and the densest of the country, with 600 inhabitants per $\mathrm{km}^{2}$ compared to an average of 51.4 at the national level. The city is characterized by a high rate of urban sprawl, which can be attributed to many factors. Population growth is a major source of increased housing needs, and particularly of self-built housing. Taken in conjunction with the isotropic nature of the city, this means that the outskirts of the city experience high levels of development pressure. This situation is compounded by the fact that newest residents prefer to be homeowners and therefore seek empty lots on which to build new homes, which is possible only in the periphery. According to the statistical yearbook of 2006, approximately $52.2 \%$ of the residents in Ouagadougou are homeowners, and about half of homeowners possess legal property papers (Boyer and Delaunay, 2009). Living on the periphery of the city can reduce quality of life since it is associated with an increased distance from city amenities and thus increased transport costs and travel time. As a result, a household's choice of residential location is an important determinant of its commuting requirements. It is important to note that Ouagadougou suffers from a lack of adequate transportation infrastructure, both public and private (Boyer and Delaunay, 2009). In the context of urban sprawl and the necessity for further urban improvements, there is significant development pressure on the city's remaining natural assets. The urban park that exists in Ouagadougou today was created from a larger natural forest called the "Bois de Boulogne", from the "Mossi" 
kingdom that formerly occupied the area. In January 2001, a part of the "Bois de Boulogne" (about $265 \mathrm{Ha}$ ), was transformed into what is now the urban park Bãngr-weoogo, and opened to the public for recreation purposes and educational activities. Given the environmental degradation the city has experienced over the years, the creation of the park was motivated by ecological, human, and social objectives. A formal ban on alternative uses exists for the park, which prohibits certain types of development (e.g. agricultural plots, houses, and industrial areas). Figure 1 portrays the park location (see below).

Figure 1: Park location

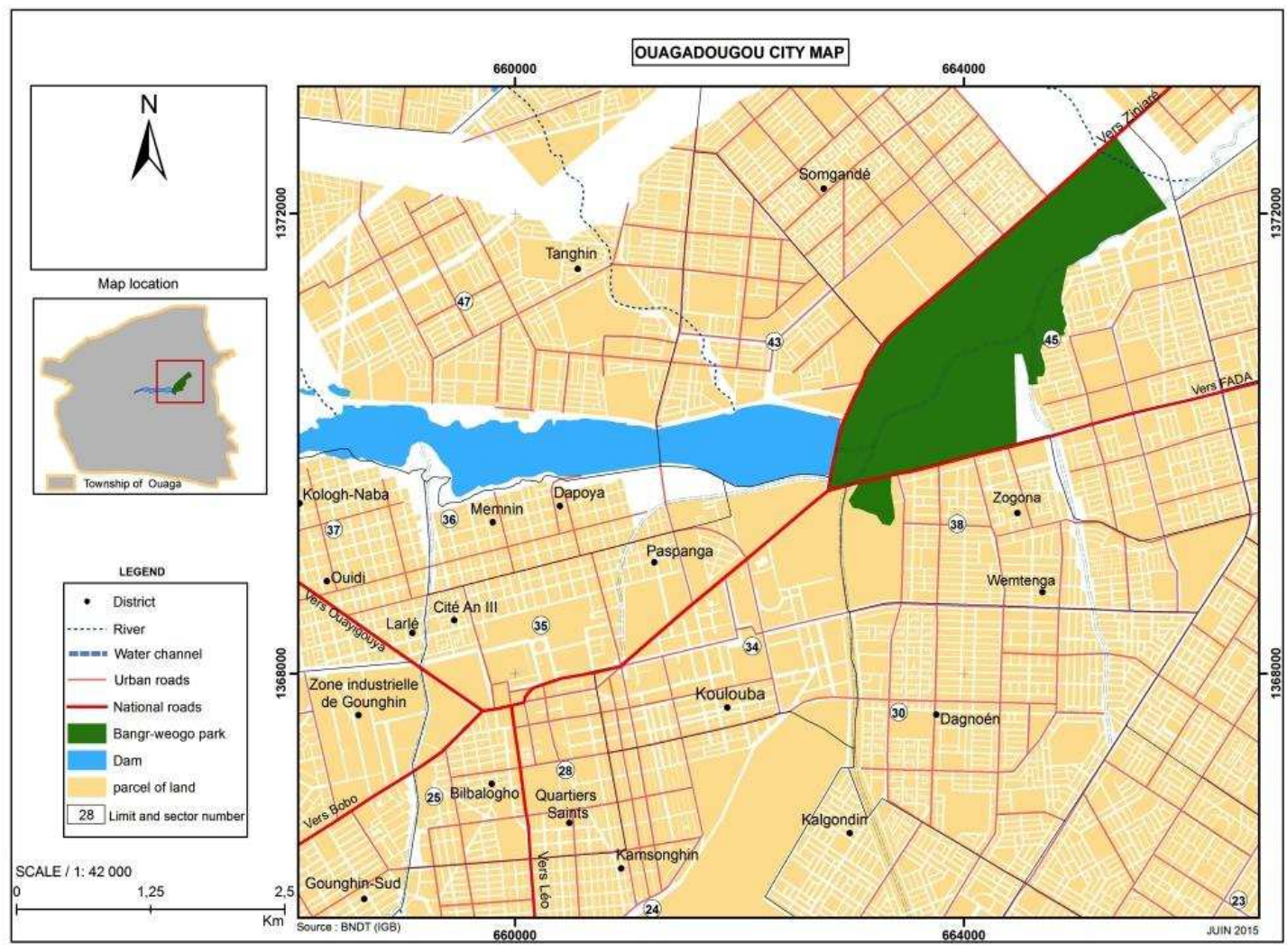




\section{The model: choice experiment and experimental design}

Studies on residential location choice have utilized both theoretical and empirical methods. Among empirical studies, most have modeled choices using versions of the discrete choice model developed by McFadden (1978). In this section, the choice experiment model used here is described.

\subsection{The choice experiment}

The purpose of this study is to estimate variations in household welfare that result from proximity to an urban park and to the workplace. Because these benefits are related to several measurable attributes of housing choice, choice experiment is the most suitable non-market valuation method by which to analyze these attributes (Hanley et al., 1998). This method is derived from Lancaster's (1966) consumer theory, which states that the utility provided by a good can be decomposed into the values of its different characteristics (Adamowicz et al., 1998). This theory is combined with McFadden's (1973) random utility theory which states that it is not possible to identify all of the factors that influence an individual's utility (Baltas and Doyle, 2001).

In choice experiment, respondents are asked to choice their preferred option from a group of alternatives that includes their current situation, or the "status quo," and a "set of options" (Bennett and Adamowicz, 2001). Each alternative is described in terms levels (qualitative and/or quantitative) of a variety of attributes (characteristics). Importantly, the inclusion of the cost attribute makes it possible to estimate the marginal value of each of the other attributes in monetary terms. Thus, this design allows for the robust measurement of well-being variations by estimating the relative elasticity of the attributes to the price (Sener et al., 2011). 


\subsection{Experimental design}

The experimental design in this study broadly consists in identifying the attributes of residential location choice and the variation in the levels of these attributes. According to the literature, several characteristics may explain residential location choice. These include attributes such as the size of dwelling, the facilities the dwelling is equipped with, features of the surrounding neighborhood, proximity to the workplace, proximity to other places of interest, the presence of pollution and/or amenities, etc. The first step in designing the experiment consisted of conducting interviews with residents of Ouagadougou in order to identify the relevant characteristics of residential location choice in this specific geographic and cultural context. From these interviews, five characteristics were selected, one of which was not commonly found in the literature: the presence of relatives in the area. The number of attributes included in a choice experiment has to be limited in order to minimize cognitive demands made on respondents, as well as for statistical reasons (Bennett and Blamey, 2001). Indeed, according to Louviere et al. (2008), the more attributes included in the choice experiment, the less consistent respondents' choices become. The five attributes retained in this study are summarized in Table 1 and defined below: 
Table 1: Attributes description

\begin{tabular}{|c|c|}
\hline Attributes & Levels \\
\hline Distance to urban park $(\mathrm{Km})$ & $\begin{array}{ll}\text { 1. } & -50 \% \\
\text { 2. } & \text { current } \\
\text { 3. } & +50 \%\end{array}$ \\
\hline Distance to workplace $(\mathrm{Km})$ & $\begin{array}{l}\text { 1. }-50 \% \\
\text { 2. current } \\
\text { 3. }+50 \%\end{array}$ \\
\hline Presence of relatives in the area & $\begin{array}{l}\text { 1. Yes } \\
\text { 2. No }\end{array}$ \\
\hline Size of house & $\begin{array}{l}\text { 1. decrease (-1 room or size) } \\
\text { 2. current } \\
\text { 3. increase }(+1 \text { room })\end{array}$ \\
\hline Price/rent of house (Euro $€$ ) & $\begin{array}{l}\text { 1. }-30 \% \\
\text { 2. }-20 \% \\
\text { 3. }-10 \% \\
\text { 4. current } \\
\text { 5. }+10 \% \\
\text { 6. }+20 \%\end{array}$ \\
\hline
\end{tabular}

The housing size is an attribute that is commonly featured in the residential location choice literature. Indeed, housing characteristics play an important role in the choice of accommodations and this finding has been confirmed in many studies. Taking into account the fact that the exact amount of surface space was rarely known among the respondents in this sample, and that some dwellings contain only one room, we were not able to collect reliable data on the actual surface of rooms in most respondents' residents. As a result, we simply used a reasonable variation in house size as attribute levels and define this attribute as a dummy 
variable in the analysis (decrease and increase of rooms' size or number relatively to the current situation);

Presence of close relatives is included in this choice set, which is a specificity of this study. During the interview process, this attribute frequently arose as an important consideration in the choice of housing location, and this suggested that a relative in the area plays a significant role in residential choice. Boyer and Delaunay, (2009) report a respondent comment that corroborates this finding: "In Africa, when you do not have your family next door, you should know that you will suffer". As mentioned above, the problem of transportation and communication infrastructures is a reality in Burkina Faso. Then, in these conditions, access to mobility becomes a prerequisite for getting out of the residential environment and co-operating with other social groups (especially family members). People remain confined to their environment and geographical proximity contributes to building the social link by facilitating exchanges and meetings (Bonvalet et al., 1999). Being in close proximity to relatives is therefore not only socially enjoyable, but may also be beneficial in the case of emergencies or in terms of having access to the types of information that circulate among extended family members, whether in cities or rural areas.

The distance to the workplace and the distance to Bãngr-weoogo are our attributes of interest in this study. Several studies have highlighted the important role that distance to the workplace and to other amenities have on residential choice ( Gayda, 1998; Earnhart, 2001, 2006; Pérez et al., 2003; Kim et al.b, 2005; Kim et al., 2005a; Ng, 2008; Frenkel et al., 2013; Wu et al., 2013; Tu et al., 2016). Only a few of them, however, have used simultaneously both characteristics to explain residential choice (T.-K. Kim et al., 2005b), and this highlights another contribution of the current study. In the choice experiment we design, both of the attributes of interest, i.e. distance to the workplace and distance to the park, vary between three levels (the current distance as well as two variations around it). We took these attributes into 
account in terms of distances because people tend to understand these better than attributes described in terms of the cost or duration of travel. Note that these attributes are measured in kilometers and considered as such in results' interpretation.

The price of housing is a crucial attribute for the choice experiment method. It measures the change in the welfare of respondents following a change in the level of another attribute ceteris paribus. Whereas renters are typically very aware of the amount they spend on monthly rent, this attribute can be more difficult for owners to quantify. As a result, we asked respondents to consider the type of habitat and the geographical location of their house and to estimate how much rent they would demand if they were to rent their house. This approach allowed including homeowners in the same treatment as renters (further, we try to see if they react differently). In this study, we use the percentage change in price as in Phaneuf et al. (2013) and Tu et al., (2016).

After the attributes and attributes' levels have been selected, we address the experimental design. This includes the generation of the choice sets that the respondent will face. The combination of the above attributes and their levels generates a large number of profiles it is possible to present to each respondent $(3 * 3 * 3 * 2 * 6=324)$. Presenting all of these options is obviously unrealistic in terms of both time and cognitive effort. As a result, we applied an orthogonal design (using Ngene 1.1.2) without a-priori parameters, used to reduce the number of profiles when satisfying attributes' levels balance and estimating independently all parameters. Ngene has a great flexibility and permit to generate designs with any number of choice situations, alternatives, attributes and attribute levels while maintaining attribute level balance (ChoiceMetrics, 2012). We created three blocks of four choice sets. Each respondent faced one of these blocks that included four choice sets. Each set asked respondents to choose from two housing alternatives as well as the respondent's current house (the status quo). An example choice set is presented in Table 2 (see below). 
Table 2: Example choice set

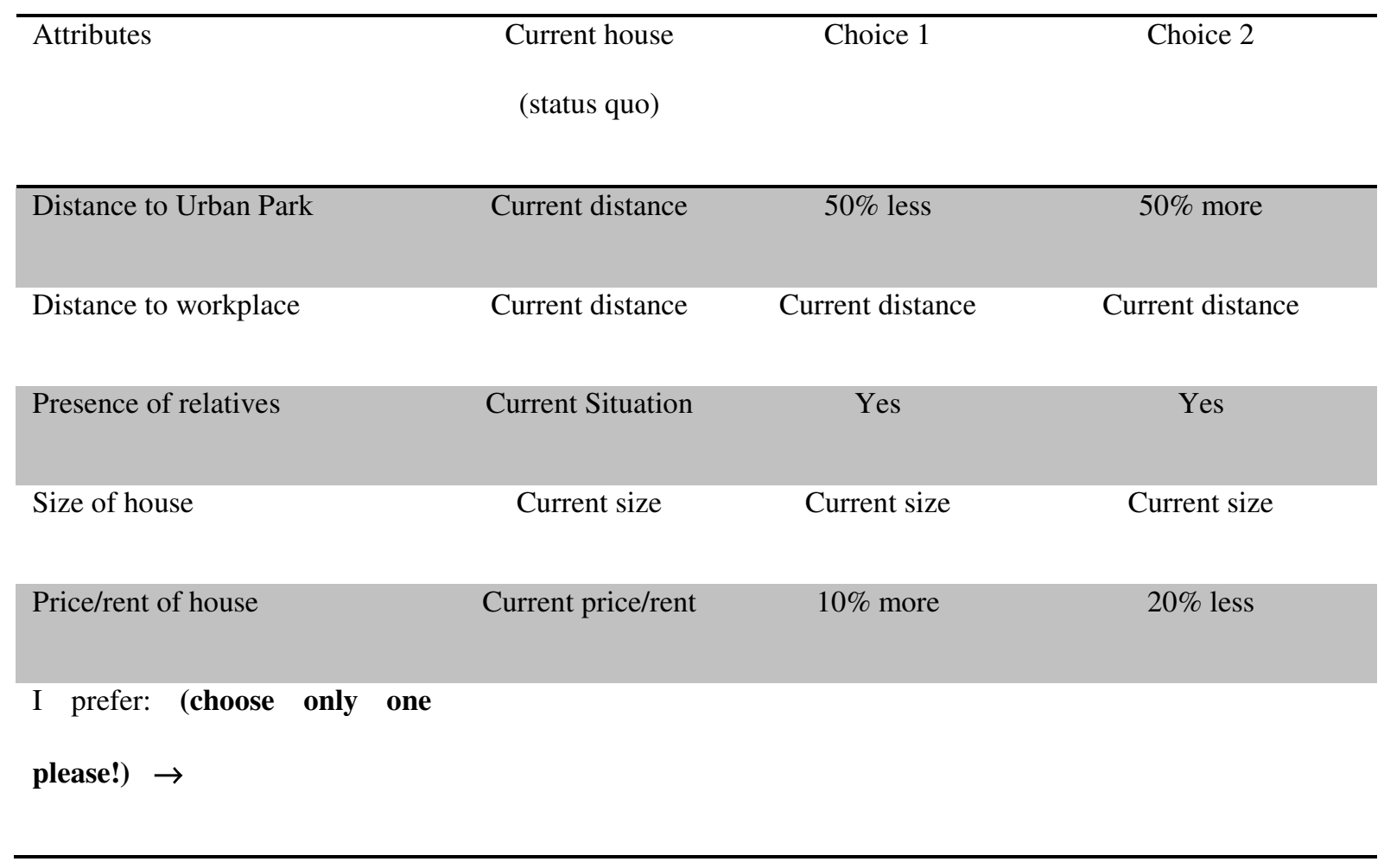

We expect that an increase in the rent and a decrease in the housing size may negatively impact inhabitants' wellbeing, and an increase in housing size and a decrease in the distance to the workplace may positively impact it. We are less certain of how proximity to the urban park in Ouagadougou may interact with distance to the workplace, and specifically whether these two attributes will exhibit complementarity or substitutability. Finally, as suggested from focus group interviews, we expect that proximity to relatives will have a positive impact on household welfare.

\subsection{Survey and data}

The survey is based on that of Tu et al., (2016) and consists of four (4) parts. we use the socalled "pivot design" in which the choice sets are built around the level of revealed attributes (Train and Wilson, 2008). The "status quo" and additional attribute levels are specific to each 
individual. Several other studies have also used the pivot design in choice experiment (see Hensher and Rose, 2007; Hensher, 2004; Train and Wilson, 2008; Tu et al., 2016). Respondents are asked to choose their preferred option from a set of options that includes their current house (the status quo) and a set of other possible houses (the alternatives). This decision scenario is elicited four times.

The survey was implemented by the author in the city of Ouagadougou between July and August 2014. About 300 people were surveyed, yielding 284 completed usable questionnaires for analysis. In order to maximize respondent comprehension of the survey, we targeted inhabitants who were at least 18 years old and who were actively employed. It is important to note although it is difficult to judge the representativeness of our sample, we strived to randomize the geographic scope of the implementation, surveying all sectors of the city outside of the park.

Average respondent age was 30 years. The percentage of men (77.8\%) was significantly higher than that of women, while the general population census in 2006 showed a $51 \%$ proportion of men in the province. There were slightly more owners $(52.1 \%)$ than renters, which corresponds to the average of the city's region according to the statistical yearbook of 2006. In terms of household size, our sample has about 5 peoples/household. It corresponds to that of the region which is 5.13 according to the statistical yearbook of 2006 . In addition, $44.33 \%$ of respondents had a low level of income (low income being the first income class of the 3 that we have defined ( 0 to about 230 euros)) and only $11.27 \%$ felt that their location was remote compared to major places of interest. Respondent characteristics are summarized in Table 3 (see below). 
Table 3: Respondent characteristics

\begin{tabular}{|c|c|c|c|c|}
\hline & Min & Max & Mean & Stand. D \\
\hline Age (year) & 18 & 62 & 30.38 & 7.85 \\
\hline Distance to workplace (km) & 1 & 25 & 8.26 & 5.61 \\
\hline Distance to park (km) & 1 & 22 & 7.86 & 5.16 \\
\hline House size (number of rooms) & 1 & 12 & 3.65 & 2.15 \\
\hline Rent/month (Euro) & 4.6 & 1,067 & 106.9 & 136.9 \\
\hline Household size & 1 & 36 & 4.97 & 4.15 \\
\hline
\end{tabular}

\section{Percentage}

\section{Presence of relatives}

$\begin{array}{lc}\text { Male } & 78 \\ \text { Owner } & 52\end{array}$

\begin{tabular}{|cc|} 
Head of household & 57 \\
\hline Single & 59
\end{tabular}

\begin{tabular}{|c|c|c|}
\hline \multicolumn{2}{|c|}{ Safe neighborhood } & 72 \\
\hline \multirow[t]{3}{*}{ Major places } & Not near & 11.27 \\
\hline & Near & 35.21 \\
\hline & Near with good qual. & 53.17 \\
\hline \multicolumn{3}{|c|}{ Income (Euros) } \\
\hline \multicolumn{2}{|c|}{ Low (0 to 230) } & 44.33 \\
\hline \multicolumn{2}{|c|}{ Average (230 to 460) } & 35.82 \\
\hline \multicolumn{2}{|c|}{ High (more than 460) } & 19.85 \\
\hline
\end{tabular}

\section{Occupation}

Executive

Lib. and inter.

63.12

Laborer

09.57

Retirement

03.55 


\section{Econometric Specification}

\subsection{Econometric model}

The conditional logit (CL) is the basic model used for the analysis of data from choice experiment (Birol et al., 2009). It assumes that the error term " $\varepsilon$ " follows a Gumbel's distribution and is Independently and Identically Distributed (IID). This model relies on the assumption of the Independence of Irrelevant Alternatives (IIA), which stipulates that the relative probability of selection of two alternatives is not affected by the introduction or removal of an alternative. The IIA assumption is necessary for the random utility theory (Hanley et al., 1998). In this model, the probability that an individual $n$ chooses the alternative $i$ from the set $\mathrm{C}$ of the alternatives that are proposed to him corresponds to the probability that this alternative $\mathrm{i}$ is the one that gives him the greatest utility.

$$
P_{\text {in }}=P\left[V_{\text {in }}+\varepsilon_{\text {in }}>V_{j n}+\varepsilon_{j n}, \forall j \in C, j \neq i\right]
$$

Then;

$$
P_{\text {in }}=P\left[\varepsilon_{j n}<V_{i n}-V_{j n}+\varepsilon_{i n}, \forall j \in C, j \neq i\right] .
$$

From it,

$$
P_{i n}=\frac{\exp \left(V_{i n}\right)}{\sum_{j \in C} \exp \left(V_{j n}\right)}=\frac{\exp \left(\beta X_{i n}\right)}{\sum_{j \in C} \exp \left(\beta X_{j n}\right)}
$$

This model faces some limitations. The "IIA" assumption may be violated for many reasons (for example, the use of correlated attributes). Additionally, although heterogeneity may exist among respondents, this model assumes that preferences are homogenous, and does not take into account possible correlations among error terms (Birol et al., 2009). Taking into account heterogeneity in economic analysis, in contrast, allows for unbiased parameter estimation and 
demand forecasting because it statistically accounts for variations in individual characteristics (Boxall and Adamowicz, 2002). For these reasons, another model will be needed in order to estimate unbiased parameters.

The latent class logit model presents an alternative to the conditional logit. In this model, the population is represented as a finite number of segments or classes. Because heterogeneity among individuals is understood to affect preferences, it is necessary to first identify the factors that drive this heterogeneity (Boxall and Adamowicz, 2002). The heterogeneity of preferences is represented by an endogenous, unobservable (i.e. latent) distribution of the categories that characterize respondents (Bonnieux and Carpentier, 2007). Preferences are assumed to be homogeneous within each class, but are allowed to vary between classes. The number of segments is determined endogenously by variations within the data, and segments are assigned according observable socio-economic characteristics. According to Allenby and Rossi (1998), the latent class logit underestimates the degree of heterogeneity that may be present in a sample. The mixed logit (ML) model, developed by McFadden and Train, (2000) has been increasingly used to take into account the heterogeneity of preferences in discrete choice models. It accounts for heterogeneity by allowing parameters to vary randomly over individuals. In most cases, respondents' utility follows a multivariate normal distribution. Estimation under these conditions is easier, and the mixed logit model solves the problem of IIA (McFadden and Train, 2000). It has been successful in this respect over time and across a variety of areas. In this model, the utility is given by the formula:

$$
U_{\text {inc }}=\left(\beta+\eta_{n}\right) X_{\text {inc }}+\varepsilon_{\text {inc }},
$$

where $\eta_{n}$ is the standard deviation of the $\mathrm{n}^{\text {th }}$ person compared to the average. The probability that an individual chooses option $\mathrm{i}$ over option $\mathrm{j}$ is given by: 


$$
P_{i n c}=\int \frac{\exp \left(X_{i n}^{\prime} \beta\right)}{\sum_{j=1}^{J} \exp \left(X_{j n}^{\prime} \beta\right)} f(\beta \mid \theta) d \beta,
$$

where $f(\beta \mid \theta)$ represents the distribution function of $\beta$.

Econometric estimations based on this specification make it possible to calculate the marginal willingness to pay for the attributes included in this study. This analysis is presented in the next section.

\subsection{Modeling willingness to pay and willingness to pay space}

Marginal willingness to pay estimates respondents' preferences for the various attributes of location choice. There are two ways to calculate these estimates. The first is called marginal willingness to pay (or preference space). It is obtained through the ratio of the attribute's coefficient to the price coefficient obtained from models such as CL and ML models:

$$
W T P_{\alpha}=-\frac{d x_{p}}{d x_{\alpha}}=-\frac{d V / d x_{\alpha}}{d V / d x_{p}}=-\frac{\beta_{a}}{\beta_{p}}
$$

where $x_{\alpha}$ and $x_{p}$ refer to the attribute $\alpha$ and the monetary attribute, respectively, and $\beta \alpha$ and $\beta p$ their parameters as estimated mainly from the conditional logit.

In the case of the Mixed Logit models, the above ratio provides a skewed distribution of willingness to pay. Thus, Train and Weeks (2005) suggested an estimate of willingness to pay space. Previous studies have shown that this estimate is more realistic and exhibits a low distribution density at extreme values (Train and Weeks, 2005) and Scarpa et al., (2008) reported that the estimation through WTP space had a better fit in their empirical study. The "willingness to pay space" approach consists of reformulating the utility function. In this case, before estimating the random parameter model, the model is configured a priori, and thus 
directly yields the marginal WTP, or WTP space, instead of the attributes' coefficients $\beta_{n}$, and the monetary attribute is normalized to 1 .

In this study, the value of the utility of individual n, choosing housing option " $i$ " from the set of selection $\mathrm{C}$ is given by:

$U_{i n c}=\beta_{n} X_{i n c}+\varepsilon_{i n c}, \quad i=1, \ldots, \mathrm{I}, \quad n=1, \ldots, \mathrm{N}, \quad c=1, \ldots, \mathrm{C}$

Where $X_{\text {inc }}$ is the observed attribute vector and $\beta_{n}$ the vector of individual specific taste coefficient with a density $f(\beta \mid \theta)$ where $\theta$ are the parameters of the distribution, and $\varepsilon_{\text {inc }}$ is a random error term identically and independently distributed to extreme values.

The transformation of the equation above gives:

$U_{i n c}=\alpha_{n} p_{i n c}+\beta_{n} X^{\prime}{ }_{i n c}+\varepsilon_{i n c}, \quad i=1, \ldots, \mathrm{I}, \quad n=1, \ldots, \mathrm{N}, \quad c=1, \ldots, \mathrm{C}$

where $p_{\text {inc }}$ represents the monetary attribute and $X^{\prime}{ }_{i n c}$ represents the vector of other nonmonetary attributes in the model. Elements $\alpha_{n}$ and $\beta_{n}$ are the estimated parameters associated with these attributes, and $\varepsilon_{\text {inc }}$ the random error term with a variance:

$$
\operatorname{Var}\left(\varepsilon_{i n c}\right)=k_{n}^{2}\left(\frac{\pi^{2}}{6}\right)
$$

for $k_{n}^{2}$, the scale parameter of the $\mathrm{n}^{\text {th }}$ individual.

As a remember, in the preference space case, the WTP would be obtained by the ratio $-\beta_{n} / \alpha_{n}$. With ML model, both price and attribute parameter are random. This leads to a skewed distribution due to the ratio of two random variables.

Dividing the transformed utility equation by $k_{n}$, we obtain:

$$
U_{i n c}=-\lambda_{n} p_{i n c}+c_{n} X^{\prime}{ }_{i n c}+\varepsilon_{i n c}
$$


for $\lambda_{n}=\alpha_{n} / k_{n}, c_{n}=\beta_{n} / k_{n}$ and $\varepsilon_{i n c}=\varepsilon_{i n c} / k_{n}$. This corresponds to the model where the WTP for an attribute is obtained through the ratio $\gamma_{n}=c_{n} / \lambda_{n}$ and doesn't change the household's behavior according to Train and Weeks, (2005).

This equation is equivalent to the following:

$$
U_{\text {inc }}=\lambda_{n}\left[-p_{\text {inc }}+\gamma_{n}^{\prime} X_{\text {inc }}\right]+\varepsilon_{\text {inc }}
$$

\subsection{Estimation results}

In total, 284 questionnaires are used in this analysis. The survey was conducted randomly with people aged 18 and over in Ouagadougou, Burkina Faso. Attributes such as "presence of relatives," and "dwelling size" are coded as categorical dummy variables in order to facilitate the processing and interpretation of results.

The first model used is the conditional logit, which considers all preferences as homogeneous. According to Hausman's test, the IIA assumption is respected at the 5\% level.

The parameters obtained from this model are almost all significant at the critical threshold of $5 \%$, except for some attributes as the Alternative Specific Constant (ASC), reflecting an indifference to change. Thus, increased distance to the urban park or to the workplace reduces the likelihood of choosing an alternative house. Additionally, having a relative in the area increases the chances of choosing an alternative. As expected, increases in rent (captured by the monetary attribute) reduce the probability of selecting an alternative (see tables 4 and 5 below). 
Table 4: Estimation results

\begin{tabular}{|c|c|c|}
\hline & $\begin{array}{c}\text { Condi } \\
\text { LL: }\end{array}$ & \\
\hline Attributes & Estimators & Standard error \\
\hline ASC & -0.038 & $(0.075)$ \\
\hline Distance to work*rent & $0,018 * *$ & $(0,015)$ \\
\hline Distance to park*income & $2.62 .10-7$ & $\left(1.32 .10^{-7)}\right.$ \\
\hline Distance to workplace & $-0.041 * * *$ & $(0.014)$ \\
\hline Distance to park & $-0.066 * *$ & $(0.028)$ \\
\hline Presence of relatives & $0.67 * * *$ & $(0.084)$ \\
\hline Decrease in house size & $-0.76 * * *$ & $(0.115)$ \\
\hline Increase in house size & 0.034 & $(0.093)$ \\
\hline Rent & $-0.722 * * *$ & $(0.241)$ \\
\hline
\end{tabular}

*Significant at $10 \% \quad{ }^{* *}$ significant at $5 \% \quad{ }^{* * *}$ significant at $1 \% \quad$ [] not significant

In this section, we comment on the direction of change without addressing the magnitude of these coefficients. The next section addresses our main interest in this paper, that is, the assessment of preferences through marginal willingness to pay. 


\subsection{Welfare analysis}

Here, we estimate variations in welfare through the monetary valuation of respondents' preferences for the various residential attributes. This estimation is accomplished through the marginal willingness to pay and the marginal willingness to pay space methods described above. Results are shown in Tables 5 below. The final willingness to pay is obtained by multiplying the estimator by the average rent. Considering the Mixed Logit model for example; respondents are willing to pay $10.8 €$ per $\mathrm{km}$ for decrease in the distance to the urban park Bãngrweoogo $\left(\mathrm{WTP}=\beta_{k} *\right.$ Average rent $\left.=0.101 * 106.9=10.8 € / \mathrm{Km}\right)$. 
$\underline{\text { Table 5: }}$ Marginal willingness to pay and willingness to pay space

Marginal willingness to pay

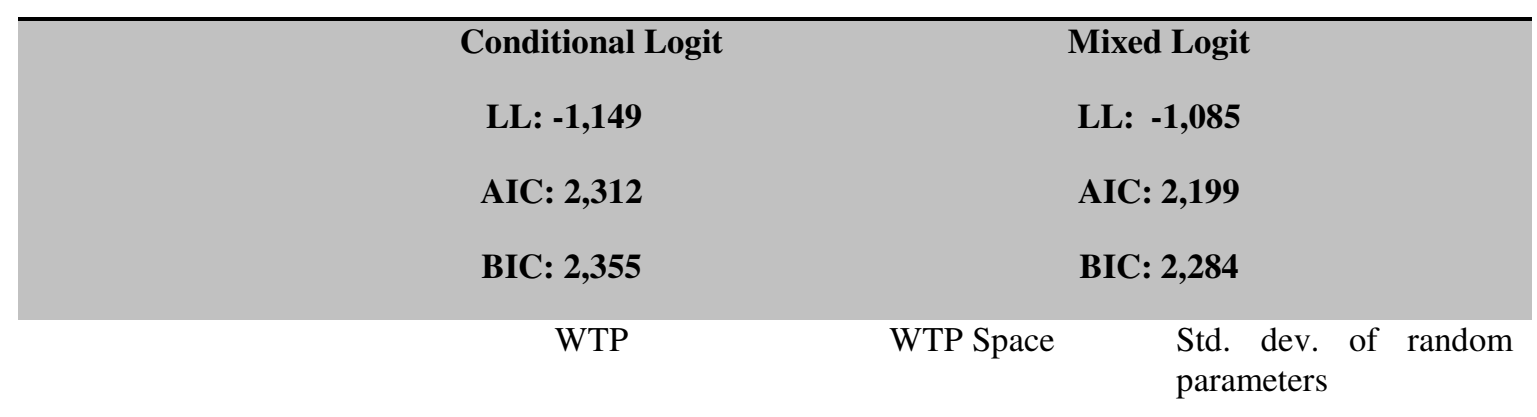

\begin{tabular}{ccc} 
Distance to work*rent & $3.63 \times 10^{-7 * *}$ & $4.4 .10^{-7 * *}$ \\
& & $\left(1.91 .10^{-7)}\right.$ \\
\hline $\begin{array}{c}\text { Distance to } \\
\text { park*income }\end{array}$ & - & 0.034 \\
\hline
\end{tabular}

$\begin{array}{cccc}\text { ASC } & - & -0.168 & 1.041 * * * \\ & & (0.123) & \\ \text { Distance to workplace } & -0.057 * * & -0.068 * * * & 0.058\end{array}$

$(0.021)$

\begin{tabular}{cccc} 
Distance to park & $-0.092 * * *$ & $-0.101 * *$ & $0.062 * *$ \\
& & $(0.044)$ & \\
\hline Presence of relatives & $0.927 * * *$ & $1.138 * * *$ & $1.409 * * *$
\end{tabular}

$(0.166)$

\begin{tabular}{lccc} 
Decrease in house size & $-1.051 * * *$ & $-1.246 * * *$ & $1.560 * * *$ \\
Increase in house size & - & $(0.232)$ & $1.660 * * *$ \\
& 0.060 & \\
\hline
\end{tabular}

*Significant at 10\% $\quad * *$ significant at 5\% $\quad * * *$ significant at $1 \% \quad[]$ not significant ( ) standard error

As shown in the Table 5, many variables are significant and have the same sign in all models, with the exception of the ASC, the variable distance to work*rent and the variable "increase in house size" regardless of the model. 
The negative signs associated with proximity to the workplace and proximity to the park show a loss of well-being regardless of the model. This indicates that the farther a residence is located from either the park or the workplace, the lower the well-being of the household. We have interacted the variables "distance to the park" and "distance to workplace" in the ML models in order to determine their degree of dependency. This interacted variable is non-significant and reflects the fact that these attributes are neither substitutable nor complementary. Rather, they appear to be independent. Furthermore, an increase in distance to the park is associated with a higher willingness to accept than an increase in distance to the workplace. In addition, this interacted variable led to a decline in the quality of the model, and thus we do not include this term in the final specification.

The attribute "presence of relatives" receives the highest willingness to pay and highlights the importance of this sociological aspect in a developing country such as Burkina Faso, where social ties remain important regardless of the place of residence (urban or rural). The attribute that receives the highest willingness to accept in all models is the reduction in the size of the dwelling. The loss in utility associated with a decrease in house size is significant, especially considering that $35 \%$ of respondents are already unsatisfied with the size of their current residence.

The interacted variable "distance to work*rent" in Table 5 measures households' sensitivity to distance to the workplace as rent changes. This variable is significant and positive, which indicates that an increase in rent is accompanied by a reduction in distance to the workplace even though the estimated parameter and therefore the WTP is low and tends to be insignificant. In other words, an increased rent would push people to move near their workplace in order to minimize the distance and consequently travel cost. 
The interacted variable "distance to the park*income" in Table 5 measures the households' sensitivity to increasing distance to the park as income changes, and is not significant. Thus, an increase in income does not necessarily lead respondents to move either closer to or further from the park. It is normal to expect other interactions such as distance to work* income or distance to the park*rent. Note that these interactions have been tested and they were not significant and abased the overall quality of our model, hence their absence in the final specification.

Finally, standard deviation values in the ML model demonstrate that preferences are in fact heterogeneous in this sample. In this case, more than $88 \%$ of respondents have a positive WTP to live close to their place of work, $94 \%$ of people have a positive WTP to live close to the park, and $80 \%$ have a positive WTP to have a relative in the area. These values are calculated as $\varphi[-($ mean parameter estimate / the random parameter standard deviation $)]$, where $\varphi[x]$ is the cumulative standard normal distribution.

\section{Discussion}

The results show that, on average, respondents are indifferent between keeping their current home or moving. This result could be unexpected because in most studies, the Business As Usual (BAU) case is chosen due to the aversion to change. Our result does not indicate a balanced housing market and the fact that some areas are not under the pressure of strong demand in the city. The analysis also demonstrates that preferences for housing characteristics are heterogeneous. As it has also been mentioned in other studies (Earnhart, 2001; Kim et al., 2005a; Wu et al., 2013; Tu et al., 2016), we find that living closer to the urban park, as well as to the workplace increases the well-being of residents of Ouagadougou. However, these two 
features are neither substitutes nor complements. A somewhat unexpected result is that distance to the park is associated with a higher willingness to accept than distance to the workplace. Indeed, the loss in utility generated by an increase in distance to the park is greater than that generated by an increase in distance to the workplace. The high value that respondents place on proximity to the park may partly reflect first the recreational value of Bãngr-weoogo, the assessment of which by the travel cost method can be difficult due to its location in the heart of the city (see Darling, 1973). Additionally, it reflects the value of amenities such as climate regulation, and to a lesser extent that of the landscape.

The attribute that reflects the presence of relatives in the area receives the largest willingness to pay regardless of the calculation method used (WTP or WTP Space). Because this attribute has not been empirically studied before now, no reference figures exist for comparison. However, this finding is consistent with African traditions. Indeed, in Burkina Faso, the importance of proximity to family members is well expressed by the saying "We consider an orphan, in the broad sense of the term, one who lives in an area where he has no relatives".

Any substantial increase in rent results in a relocation of residents near to their workplace as demonstrated by the interacted variable "Distance to work*rent" in the Mixed Logit model. In other words, inhabitants are willing to pay more when the distance from the house to the workplace decreases. This finding seems intuitive and in line with work by Nowotny (2011), Renkow and Hoover (2000), and Van Ommeren et al. (1999).

Results indicate that the characteristics of the dwelling itself remain a very important factor in the likelihood of an alternative being chosen. We were not able to consider all possible characteristics in this study (that is not the interest of our study), but we were able to take them into account to some degree through the inclusion of a common attribute in the literature that is the housing size. On average, people are indifferent to increases in the size of their house 
(contrary to what has been found by Earnhart 2001, 2006; Frenkel et al. 2013). Notably, 65\% of respondents are satisfied with their current house size and experience a loss of utility when this size declines.

We initially hypothesized that preferences may differ between owners and renters, between heads of households and other household members, as well as between those who live far from the workplace and/or the park compared to those who live closer to these places. The conditional logit applied for each group (owners, renters...) confirms these intuitions (see Table 6 below). In fact, homeowners are less sensitive to rent variation, which is to be expected because they do not pay rent. Also, owners are pro-status quo. This can be explained by the fact that residential mobility is reduced (Boyer and Delaunay, 2009), especially for owners who are generally reluctant to move due to the high investment that is may require. Overall, homeowners tend to care about proximity to workplace whereas renters do not. The fact that it is more difficult for owners to move may explain this finding. In addition, heads of households are sensitive to the proximity to amenities and the level of rent, while other household members are not. It was expected because the heads of households move to work and support the other members of the household, who have little to do with decisions regarding residential location. Finally, inhabitants who are farthest from the workplace and/or the park compared to the mean are sensitive to changes in this proximity, while the others are not. This finding may be explained by the concept of geographical discounting. According to this concept, individuals prefer being close to amenities that they value most, which could explain the high sensitivity to changes in this distance among those who are already very far away from these amenities. 
Table 6: willingness to pay per categories of respondents (conditional logit)

\begin{tabular}{|c|c|c|c|c|c|c|}
\hline & \multicolumn{2}{|c|}{ Owner } & \multicolumn{2}{|c|}{ Head of household } & \multicolumn{2}{|c|}{ Distances $>$ average } \\
\hline & Yes & No & Yes & No & Yes & No \\
\hline & $\begin{array}{l}\text { LL : - } \\
598.45\end{array}$ & $\begin{array}{l}\text { LL : - } \\
547.03\end{array}$ & $\begin{array}{l}\text { LL : - } \\
652.77\end{array}$ & $\begin{array}{l}\text { LL : - } \\
479.59\end{array}$ & $\begin{array}{l}\text { LL : - } \\
244.32\end{array}$ & $\begin{array}{l}\text { LL : - } \\
901.27\end{array}$ \\
\hline & $\mathrm{N}: 149$ & $\mathrm{~N}: 135$ & $\mathrm{~N}: 161$ & $\mathrm{~N}: 123$ & $\mathrm{~N}: 62$ & $\mathrm{~N}: 222$ \\
\hline ASC & -0.054 & 0.018 & 0.072 & -0.18 & -0.032 & -0.022 \\
\hline Distance to workplace & $-0.025^{*}$ & -0.018 & $-0.027 * *$ & -0.014 & $-0.031 * *$ & -0.012 \\
\hline Distance to park & $-0.04 * *$ & $-0.26 *$ & $-0.027 * *$ & $-0.044 * *$ & $-0.055^{* * *}$ & -0.014 \\
\hline Presence of relatives & $0.67 * * *$ & $0.68 * * *$ & $0.82 * * *$ & $0.42 * * *$ & $0.56 * * *$ & $0.71 * * *$ \\
\hline $\begin{array}{l}\text { Decreasing of house } \\
\text { size }\end{array}$ & $-0.83 * * *$ & $-0.69 * * *$ & $0.041 * * *$ & $-1.28 * * *$ & $-0.95 * * *$ & $-0.72 * * *$ \\
\hline $\begin{array}{l}\text { Increasing of house } \\
\text { size }\end{array}$ & -0.11 & 0.20 & $0.27 * *$ & -0.22 & -0.054 & -0.069 \\
\hline Rent & -0.48 & $-0.93 * * *$ & $-1.10 * * *$ & -0.12 & $-0.24 * *$ & $-0.83 * * *$ \\
\hline
\end{tabular}

*Significant at 10\% $\quad * *$ significant at 5\% $\quad * * *$ significant at $1 \% \quad$ [] not significant

\section{Conclusion}

Many studies have examined the factors that drive households' residential choices, particularly in developed countries, and heterogeneity of preferences is often assumed in this extensive literature. These studies allow researchers not only to understand the monetary value of different attributes, but also the interactions and tradeoffs between attributes.

In this study we aimed to better understand the residential location choices of the inhabitants of Ouagadougou in terms of several targeted attributes. Choice experiment method is in fact the only method able to take into account the trade-offs between socio-demographic and location variables and to identify the sensitivity of the various population segments to these different attributes (Frenkel et al., 2013). We utilized a pivot method technique to design this choice 
experiment, which incorporates both the current housing characteristics of respondents as well as hypothetical levels that vary around these characteristics. Changes in well-being were assessed through measures of "marginal willingness to pay" and "willingness to pay space". The unexpected result is that the distance to the park is associated with a higher willingness to accept than distance to the workplace in a country in which environmental questions are generally considered of lower priority. The existence of substitution or complementarity effect between attributes such as the distance to the workplace and distance to an environmental amenity was examined and they seem independent. One important contribution of this study arises from the discovery that family ties are very important to African, and therefore ignoring them in the context of similar residential choice studies would be a mistake. Excepting any errors of omission, this appears to be the first study that uses choice modeling to evaluate the role of green spaces on residential choices in Africa.

These results have implications for urban land-use planning and shed light on the importance of environmental amenities in residential location choice. By demonstrating that people value proximity to the urban park in Ouagadougou, this study provides evidence that green spaces are indeed considered attractive. Thus it suggests, furthermore, that preservation efforts targeting green spaces are likely to meet with widespread public support. These results can be taken into consideration during the course of future development, planning, and afforestation projects in Ouagadougou in which sustainability is a priority.

\section{Acknowledgments:}

We would like to thank Serge Garcia, Douadia Bouguerara, Raphaële Preget, Sophie Thoyer, Jean-Michel Salles, Alexandre Sauquet and our CEE-M colleagues for helpful comments and suggestions. 


\section{Cited references}

Adamowicz, W., Boxall, P., Williams, M., Louviere, J., 1998. Stated Preference Approaches for Measuring Passive Use Values: Choice Experiments and Contingent Valuation. Am. J. Agric. Econ. 80, 64-75.

Alonso, W., 1964. Location and land use. Toward a general theory of land rent. Locat. L. use. Towar. a Gen. theory L. rent.

Baltas, G., Doyle, P., 2001. Random utility models in marketing research : a survey. J. Bus. Res. 51, 115-125.

Barbosa, J.A., Bragança, L., Mateus, R., 2012. How to address sustainability at the city level, in: Urban Regeneration. pp. 751-760.

Baur, J.W.R., Tynon, J.F., Gómez, E., 2013. Attitudes about urban nature parks: A case study of users and nonusers in Portland, Oregon. Landsc. Urban Plan. 117, 100-111.

Bennett, J., Adamowicz, V., 2001. Some fundamentals of environmental choice modelling, The choice modelling approach to environmental valuation. Edward Elgar, Cheltenham, UK.

Bennett, J., Blamey, R., 2001. The choice modelling approach to environmental valuation. Edward Elgar Publishing.

Birol, E., Hanley, N., Koundouri, P., Kountouris, Y., 2009. Optimal management of wetlands: Quantifying trade-offs between flood risks, recreation, and biodiversity conservation. Water Resour. Res. 45, 1-11.

Bonnieux, F., Carpentier, A., 2007. Préférence pour le statu quo dans la méthode des programmes : illustration à partir d' un problème de gestion forestière. Rev. Econ. Polit. $117,699-717$.

Bonvalet, C., Gotman, A., Grafmeyer, Y., 1999. Proches et parents: l'aménagement des territoires. INED/PUF, Cah.

Boxall, P.C., Adamowicz, W.L., 2002. Understanding Heterogeneous Preferences in Random Utility Models : A Latent Class Approach. Environ. Resour. Econ. 23, 421-446.

Boyer, F., Delaunay, D., 2009. Ouaga 2009, Peuplement de Ouagadougou et développement urbain. Rapp. provisoire $250 \mathrm{p}$.

Brueckner, J.K., Thisse, J.-F., Zenou, Y., 1999. Why is central Paris rich and downtown Detroit poor?: An amenity-based theory. Eur. Econ. Rev. 43, 91-107.

Cavailhès, J., 2009. Le coût du logement selon sa localisation. Informations Soc. 5, 38-46.

Cavailhès, J., 2005. Le prix des attributs du logement. Econ. Stat. 381, 91-123.

Cavailhès, J., Brossard, T., 2007. Le prix des paysages périurbains. Économie Rural. 71-84.

Chhetri, P., Stimson, R.J., Western, J., 2006. Modelling the Factors of Neighbourhood Attractiveness Reflected in Residential Location Decision Choices. Stud. Reg. Sci. 36, 393-417. 
Chiesura, A., 2004. The role of urban parks for the sustainable city. Landsc. Urban Plan. 68, 129-138.

ChoiceMetrics, 2012. Reference guide: The Cutting Edge in Experimental Design 255 p.

Darling, A.H., 1973. Measuring Benefits Generated by Urban Water Parks Measuring Benefits Generated by Urban Water Parkst. Urban Water 49, 22-34.

Dou, X., Li, S., Wang, J., 2013. Ecological Strategy of City Sustainable Development. APCBEE Procedia 5, 429-434.

Earnhart, D., 2006. Using contingent-pricing analysis to value open space and its duration at residential locations. Land Econ. 82, 17-35.

Earnhart, D., 2001. Combining revealed ans stated Preference Methods to Value Environmental Amenities at Residential Location. Land Econ. 77, 12-29.

Frenkel, A., Bendit, E., Kaplan, S., 2013. Residential location choice of knowledge-workers: The role of amenities, workplace and lifestyle. Cities 35, 33-41.

Gayda, S.B., 1998. Stated preference survey on residential location choice and modal choice in Brussels, in: Transportation Planning Methods. Proceedings of Seminar D HELD at AET European Transport Conference, Loughborough University, UK, 14-18 September 1998. Volume P423.

Gervais-Lambony, P., 1994. De Lomé à Harare: le fait citadin: images et pratiques des villes africaines. KARTHALA Editions.

Hanley, N., Wright, R.E., Adamowicz, V., 1998. Using Choice Experiments to Value the Environment. Environ. Resour. Econ. 11, 413-428.

Hensher, D.A., 2004. Identifying the influence of stated choice design dimensionality on willingness to pay for travel time savings. J. Transp. Econ. Policy 38, 425-446.

Hensher, D. a., Rose, J.M., 2007. Development of commuter and non-commuter mode choice models for the assessment of new public transport infrastructure projects: A case study. Transp. Res. Part A Policy Pract. 41, 428-443.

Horner, M.W., 2004. Spatial Dimensions of Urban Commuting: A Review of Major Issues and Their Implications for Future Geographic Research. Prof. Geogr. 56, 160-173.

Horner, M.W., 2003. Exploring spatial effects on urban housing duration. Environ. Plan. A $35,1415-1429$.

Jim, C.Y., 2004. Green-space preservation and allocation for sustainable greening of compact cities. Cities 21, 311-320.

Kim, J., Pagliara, F., Preston, J., 2005. The intention to move and residential location choice behaviour. Urban Stud. 42, 1621-1636.

Kim, T.-K., Horner, M.W., Marans, R.W., 2005a. Life Cycle and Environmental Factors in Selecting Residential and Job Locations. Hous. Stud. 20, 457-473.

Kim, T.-K., Horner, M.W., Marans, R.W., 2005b. Life cycle and environmental factors in selecting residential and job locations. Hous. Stud. 20, 457-473. 
Krugman, P., 1996. Urban concentration: the role of increasing returns and transport costs. Int. Reg. Sci. Rev. 19, 5-30.

Kuchelmeister, G., Braatz, S., 1993. Urban forestry revisited. Unasylva 44.

Kuo, F.E., Sullivan, W.C., 2001. Environment and Crime in the Inner City Does Vegetation Reduce Crime? Environ. Behav. 33, 343-367.

Louviere, J.J., Street, D., Burgess, L., Wasi, N., Islam, T., Marley, A.A.J., 2008. Modeling the choices of individual decision-makers by combining efficient choice experiment designs with extra preference information. J. choice Model. 1, 128-164.

Martinez-Alier, J., 2003. The environmentalism of the poor: a study of ecological conflicts and valuation, Cheltenham. ed. Edward Elgar Publishing, UK.

McFadden, D., 1978. Modelling the choice of residential location. Institute of Transportation Studies, University of California.

McFadden, D., 1973. Conditional logit analysis of qualitative choice behavior.

McFadden, D., Train, K., 2000. Mixed MNL models for discrete response. J. Appl. Econom. $15,447-470$.

Nechyba, T.J., Strauss, R.P., 1998. Community choice and local public services: A discrete choice approach. Reg. Sci. Urban Econ. 28, 51-73.

Ng, C.F., 2008. Commuting distances in a household location choice model with amenities. J. Urban Econ. 63, 116-129.

Nowotny, K., 2011. Commuting, Residence and Workplace Location Attractiveness and Local Public Goods. Sci. Reg.

Pérez, P.E., Martínez, F.J., Ortúzar, J. de D., 2003. Microeconomic formulation and estimation of a residential location choice model: implications for the value of time. J. Reg. Sci. 43, 771-789.

Phaneuf, D., Taylor, L., Braden, J., 2013. Combining revealed and stated preference data to estimate preferences for residential amenities: A GMM approach. Land Econ. 89, 30-52.

Prager, J.-C., Thisse, J.-F., 2010. Economie géographique du développement. La Découverte $127 \mathrm{p}$.

Renkow, M., Hoover, D., 2000. Commuting, Migration, and Rural-Urban Population Dynamics. J. Reg. Sci. 40, 261-287.

Scarpa, R., Thiene, M., Train, K., 2008. Utility in willingness to pay space: A tool to address confounding random scale effects in destination choice to the Alps. Am. J. Agric. Econ. 90, 994-1010.

Sener, I.N., Pendyala, R.M., Bhat, C.R., 2011. Accommodating spatial correlation across choice alternatives in discrete choice models: an application to modeling residential location choice behavior. J. Transp. Geogr. 19, 294-303.

Train, K., Weeks, M., 2005. Discrete choice models in preference space and willingness-topay space. Springer. 
Train, K., Wilson, W.W., 2008. Estimation on stated-preference experiments constructed from revealed-preference choices. Transp. Res. Part B Methodol. 42, 191-203.

Tu, G., Abildtrup, J., Garcia, S., 2016. Preferences for urban green spaces and peri-urban forests: An analysis of stated residential choices. Landsc. Urban Plan. 148, 120-131.

Van Ommeren, J., Rietveld, P., Nijkamp, P., 1999. Job moving, residential moving, and commuting: a search perspective. J. Urban Econ. 46, 230-253.

Wu, W., Zhang, W., Dong, G., 2013. Determinant of residential location choice in a transitional housing market: Evidence based on micro survey from Beijing. Habitat Int. 39, 16-24. 